\title{
Systemic Oxidative Stress Promoted by Emissions of Particulate Matter is Attenuated by Antioxidant Supplementation
}

\author{
Fabricio Possamai ${ }^{1}$, Sílvio Avila Junior ${ }^{1}$, Danilo Wilhelm Filho ${ }^{2, *}$ \\ ${ }^{1}$ Experimental Pathophysiology Laboratory, Universidade do Extremo Sul Catarinense, Brazil \\ ${ }^{2}$ Department of Ecology and Zoology, CCB, Universidade Federal de Santa Catarina, Brazil
}

Copyright (C) 2015 by authors, all rights reserved. Authors agree that this article remains permanently open access under the terms of the Creative Commons Attribution License 4.0 International License

\begin{abstract}
Emissions of different types of airborne particulate matter (PM) is associated either with occupational contamination that affect both, workers directly exposed to the distinct PM sources such as incineration of solid residues of health services, coal mining and also coal burning derived from an electric-power plant, as well as the population living in the vicinity of such emissions. Such contamination leads to endogenous overgeneration of reactive oxygen species (ROS) in different cells and tissues and therefore to a systemic oxidative stress (OS). Enzymatic and non-enzymatic OS biomarkers were measured in the blood of workers directly and indirectly (near the emissions) exposed and also in subjects indirectly exposed living in the vicinities of these PM emissions, before and after a six months antioxidant intervention of a daily oral supplementation of vitamins C $(500 \mathrm{mg})$ and E $(400 \mathrm{mg})$. Compared to baseline values, the antioxidant intervention after 6 months was able to confer a consistent and protective effect against the systemic OS irrespective of the PM source of the airborne contaminants. The results clearly indicate that supplementation with antioxidant vitamins could be recommended in order to attenuate the deleterious consequences of a systemic OS associated with such PM emissions.
\end{abstract}

Keywords Particulate Matter, Occupational Contamination, Oxidative Stress, Antioxidants

\section{Introduction}

We have conducted several studies on occupational contamination using the same experimental design and protocol, measuring the same OS markers in both workers directly or indirectly exposed, as well as in subjects (residents) living near the different PM emission sources: coal mining [1], incineration of solid residues of health services (SRHS) [2], and coal combustion by an electric power plant [3]. We have also demonstrated that a six month period of a combined daily antioxidant intervention with vitamins $\mathrm{E}$ and $\mathrm{C}$ (800 $\mathrm{mg}$ and $500 \mathrm{mg}$, respectively) was able to significantly attenuate such systemic OS associated with each type of airborne contamination [4], through a general improvement of both enzymatic and non-enzymatic antioxidant defenses present in the blood of all the exposed subjects and decreasing markers of oxidative damage. The main results available in the literature regarding airborne contamination associated to occupational toxicology involving coal mining, coal combustion as well as incineration of solid residues of health services (SRHS) are compared with our own findings in this study.

ROS and also nitrogen species (RNS) have been implicated in the pathogenesis of several airborne occupational contaminations such as coal dust-induced toxicity. The overgeneration of ROS, when not appropriately counteracted by enhanced antioxidant defenses, leads to a condition called systemic oxidative stress (OS) $[5,6]$. This condition is defined as an imbalance between antioxidants and oxidants in favor of the oxidants leading to cellular damage [5]. In the last years several biomarkers of OS have been used to monitor environmental contamination as well as several human disorders, reinforcing the concept that they are a very useful tool regarding environment and health assessment [6].

ROS such as superoxide anion $\left(\mathrm{O}_{2}{ }^{\circ-}\right)$, hydrogen peroxide $\left(\mathrm{H}_{2} \mathrm{O}_{2}\right)$ and hydroxyl radical $\left(\mathrm{HO}^{\circ}\right)$, are molecules mainly produced continuously at the mitochondrial cristae, as byproducts of physiological oxygen consumption [7], as well as responses to different types of environmental contamination [6]. Although these molecules participate in intracellular signaling and also in cellular defense mechanisms, increasing their concentrations leads to chain reactions that target and damage lipids, polysaccharides, proteins and DNA [6]. To quickly dispose of ROS formation and maintain their intracellular concentrations at 
physiological levels, all aerobic cells possess a panoply of antioxidant defenses, including superoxide dismutase (SOD), catalase (CAT) and glutathione peroxidase (GPx) enzymes, which are considered the first enzymatic barrier to neutralize ROS, as well as co-adjuvant enzymes, such as glutathione reductase (GR) and glutathione-S-transferase (GST), among other enzymatic and non-enzymatic defenses such as glutathione (GSH) and nutritional antioxidants as vitamin $\mathrm{E}$ and $\mathrm{C}[6,7]$.

Acting physiologically as well in response to environmental contaminants $[6,8]$, various enzymatic and non-enzymatic antioxidant defenses protect cells and tissues from further oxidative damage [7]. Such prooxidant/antioxidant imbalance was already detected in the blood of subjects chronically exposed to coal dusts, provoking enhanced lipoperoxidation in plasma $[9,10]$ together with a decline in antioxidants such as reduced glutathione [11], and antioxidant enzymes such as superoxide dismutase, glutathione peroxidase and glutathione S-transferase [10-13].

Accordingly, our laboratory demonstrated that occupational contamination related to coal mining extraction is capable to induce a systemic OS in the blood of subjects exposed to such activity, as well as in people indirectly exposed to airborne contamination who live in the neighborhood, $c a$. $15 \mathrm{~km}$ away from the mining area [1]. As a consequence, OS biomarkers have been used to monitor environmental contamination and also several human disorders [6].

Two important industrial activities are involved in the release of airborne contaminants over the world and particularly in southern Brazil. Mineral coal mining activity gives rise to environmental contamination by generating emissions of particulate matter (PM) during the extraction, beneficiation, combustion, and processing of minerals, eliciting systemic OS [1]. Similarly, incineration SRHS produces distinct contaminants such as heavy metals, dioxins, furans, poliaromathic hydrocarbons, among others, promoting systemic OS as well [2]. In addition, inherent to the process of energy generation, emissions from electric power plants also expose humans to several occupational diseases, due to the high content of redox-cycling organic chemicals, including metals, which are also implicated in the ROS overgeneration and therefore systemic OS [3].

It is worth to emphasize here, that irrespective of the type of airborne contamination, a similar systemic OS was found in subjects living near to each corresponding emission source as well, which in turn was again attenuated by the antioxidant intervention carried out for six months. It is here advocated that either an adequate nutritional dietary intervention or an antioxidant supplementation might be recommended for subjects directly and indirectly exposed to these airborne contaminations to avoid a systemic OS that probably will lead to several related occupational diseases.

The first part of this study deals with exposure to coal extraction and coal combustion, which in turn is divided in three main parts: 3.1 Coal mining: Exposure to coal mining ambience before and after an antioxidant intervention; 3.2 Coal combustion: systemic OS before and after an antioxidant intervention. The third part: 3.3 Incineration of solid residues of health services (SRHS): systemic OS before and after an antioxidant intervention. All these studies were conducted in southern Brazil, involving workers directly or indirectly exposed as well the population living (indirectly exposed) in the vicinity of the source of these airborne contaminants that were compared to blood donors living in the city of Florianópolis, $c a$. $150 \mathrm{~km}$ away from the PM emissions.

\section{Methods}

All the methodological procedures as well as the experimental design, including the geographic localization used in this study by our laboratory are published in detail elsewhere [1-4].

\section{Experimental Design}

The experimental design used in the three different studies involving PM occupational contamination was the same. Briefly, OS biomarkers were evaluated in blood samples ( $c a$. $10 \mathrm{ml}$ ) collected from a total number of 60 subjects (all males, $\mathrm{n}=20$ each group) and consisted of age and sex-matched individuals who were divided in three different groups: a) activities of coal mining or extraction, b) coal combustion in an electric-power plant, and c) incineration of solid residues of hospital services (SRHS). All participants were males and exclusion criteria included smoking, recent inflammatory diseases, chronic diseases, long term pharmacological treatment and lung injuries. Diet characteristics of the subjects were evaluated through an individual questionnaire, revealing a relatively homogenous diet and poor in nutritional antioxidants (mainly fruits and vegetables).

After the first sample collection of blood and urine from directly and indirectly exposed subjects involved in those studies, supplementation of vitamins $\mathrm{C}(500 \mathrm{mg} /$ day $)$ and vitamin E $(800 \mathrm{mg} /$ day $)$ were administered to the same exposed subjects during a period of 6 months. At the end of 6 months of antioxidant supplementation, a second sample collection was performed and again the same oxidative stress biomarkers were evaluated to verify the possible beneficial effect of vitamins $\mathrm{C}$ and $\mathrm{E}$ supplementation. The studied population, exclusion and inclusion criteria, and assays related to biomarkers of oxidative stress are described elsewhere [1-4]. Determination of heavy metal contents were carried out in urine samples, which were maintained frozen until the analyses, and were collected together with the first blood samples, as mentioned above. Atomic mass spectroscopy and all values were expressed in $\mu \mathrm{g} \mathrm{l}^{-1}$. This study was approved by the local Ethic Committee (UFSC protocols numbers 366/2005 and 166/2007). Results were expressed as mean values \pm standard error (SE). Differences between multiple groups were compared using One Way 
Analysis of Variance (ANOVA), using a post-hoc test of Dunnet. Minimal significance value was assumed at $\mathrm{p} \leq 0.05$. All determinations were performed in duplicate, excepting TBARS measurements, which were performed in triplicate.

\section{a) Regarding the exposure to coal mining:}

The subjects, both surface workers and non-workers indirectly exposed (residents living in the city of Lauro Müller, around 13,000 inhabitants and living ca. $12 \mathrm{~km}$ from the mining area), who were exposed for at least one decade to the airborne contaminants related to the coal extraction activity. Obs.: Underground miners are retired after 15 years of working activity in coal extraction.

Table 1. Demographic, biometric characteristics (age and Body Mass Index $=\mathrm{BMI}$ ) of subjects exposed directly to coal extraction, and approximately distance from the PM emission (controls and indirectly exposed). Values are expressed as mean $\pm \mathrm{SE}$ ( $\mathrm{n}=20$ each group). Values are expressed as mean $\pm \mathrm{SE}$ ( $\mathrm{n}=20$ each group). One-way ANOVA test; $* * \mathrm{P} \leq 0.01$ and $* \mathrm{P} \leq 0.05$ in relation to the group of residents.

\begin{tabular}{|c|c|c|c|c|}
\hline Groups & Age (years) & BMI & $\begin{array}{c}\text { Exposure } \\
\text { (years) }\end{array}$ & $\begin{array}{c}\text { Distance } \\
(\mathrm{km})\end{array}$ \\
\hline Controls & $33.1 \pm 7.4$ & $25.2 \pm 2.6$ & - & $\sim 150$ \\
\hline Residents & $38.7 \pm 6.9$ & $25.6 \pm 3.9$ & $37.9 \pm 11.5$ & $\sim 12$ \\
\hline Surface & $38.2 \pm 5.6$ & $27.1 \pm 3.5$ & $12.6 \pm 7.9^{*}$ & - \\
\hline Underground & $34.7 \pm 10.1$ & $26.0 \pm 3.4$ & $7.1 \pm 4.2^{* *}$ & - \\
\hline
\end{tabular}

b) Regarding the exposure to coal combustion in the electric-power plant:

The subjects workers and non-workers (residents living in the city of Capivari de Baixo, around 13,000 inhabitants and living $c a .15 \mathrm{~km}$ from the mining area), are exposed for at least one decade to the airborne contaminants related to the coal extraction activity.

Table 2. Demographic, biometric characteristics (age and Body Mass Index=BMI) of subjects exposed directly or indirectly to coal combustion at an electric-power plant, and approximately distance from the PM emission (controls and indirectly exposed). Values are expressed as mean $\pm \mathrm{SE}(\mathrm{n}=20$ each group). Values are expressed as mean $\pm \mathrm{SE}(\mathrm{n}=20$ each group). One-way ANOVA test; $* * \mathrm{P} \leq 0.05$ in relation to the group of residents.

\begin{tabular}{|c|c|c|c|c|}
\hline Groups & Age (years) & BMI & $\begin{array}{c}\text { Exposure } \\
\text { (years) }\end{array}$ & $\begin{array}{c}\text { Distance } \\
(\mathrm{km})\end{array}$ \\
\hline Controls & $33.1 \pm 7.4$ & $25.2 \pm 2.6$ & - & $\sim 150$ \\
\hline Residents & $37.1 \pm 7.7$ & $26.1 \pm 3.3$ & $\begin{array}{c}20.9 \pm \\
13.1\end{array}$ & $\sim 2-5$ \\
\hline $\begin{array}{c}\text { Office } \\
\text { workers }\end{array}$ & $39.0 \pm 11.3$ & $25.9 \pm 4.7$ & $\begin{array}{c}12.6 \pm \\
6.5^{* *}\end{array}$ & $\sim 0.2$ \\
\hline Workers & $37.3 \pm 6.4$ & $27.2 \pm 3.3$ & $\begin{array}{c}10.8 \pm \\
9.6^{* *}\end{array}$ & - \\
\hline
\end{tabular}

c) Regarding the exposure to SRHS incineration:

The workers directly exposed to the PM emission associated with the SRHS incineration were only $c a$. $100-200 \mathrm{~m}$ away from the incinerator during the working day (garbage selection activity); subjects indirectly exposed (residents, living $\sim 2-5 \mathrm{~km}$ from the incinerator plant, who were randomly selected from the population) were living in the city of Capivari de Baixo (around 25,000 inhabitants living ca. $5 \mathrm{~km}$ from the SRHS incineration plant), while the workers directly exposed were exposed as long as working at the incineration plant (in average during 3.4 years). Non-exposed subjects (controls), were also randomly selected from subjects recruited from a blood bank of the University Hospital (HU/UFSC), living $c a .110 \mathrm{~km}$ northeast from the incineration plant (Table 3 ).

Table 3 . Demographic, biometric characteristics (age and Body Mass Index $=\mathrm{BMI}$ ) of subjects exposed to SRHR incineration, and approximately distance from the PM emission. Values are expressed as mean $\pm \mathrm{SE}(\mathrm{n}=20$ each group).

\begin{tabular}{|c|c|c|c|c|}
\hline Groups & Age (years) & BMI & $\begin{array}{c}\text { Exposure } \\
\text { (years) }\end{array}$ & $\begin{array}{c}\text { Distance } \\
(\mathrm{km})\end{array}$ \\
\hline Controls & $33.1 \pm 7.4$ & $25.2 \pm 2.6$ & - & $\sim 110$ \\
\hline Residents & $37.1 \pm 7.7$ & $26.1 \pm 3.3$ & $4.9 \pm 0.2$ & $\sim 5$ \\
\hline Workers & $34.3 \pm 13.7$ & $25.2 \pm 3.3$ & $3.4 \pm 1.6$ & $\sim 0.1$ \\
\hline
\end{tabular}

\section{Results}

\subsection{Exposure to Coal Mining Ambience before and after an Antioxidant Intervention}

\subsubsection{Before the Antioxidant Intervention}

Mineral coal is the one of most abundant source of primary energy available in the world, and Brazil contributes to approximately $0.8 \%$ of the world extraction. The Brazilian mineral coal is predominantly distributed in four southern states, including the southern state of Santa Catarina, where the city of Lauro Müller is localized, which economy is based in coal extraction. The prevalent northeast direction of wind in this region rebounds in a mountain shield thereby favoring an almost continuous exposure of their residents most part of the year [14] (Figure 1) regarding the airborne contamination coming from the surface mining area. Considering that the mine is active since 1996, the subjects, both surface workers and non-workers (around 13,000 inhabitants living $c a .15 \mathrm{~km}$ from the mining area), are exposed for at least one decade to the airborne contaminants.

It is well known that air pollution particles cause increases in morbidity and mortality reported in several epidemiological studies [15]. In particular, chronic inhalation of coal dust in miners leads to several diseases such as pneumoconiosis, fibrosis, bronchitis, emphysema, cancer and other pathologic-related events [16]. In any case, a chronic inflammatory process takes place, leading to the generation of proinflammatory factors, synthesis of extra cellular matrix, fibroblast proliferation, and altering the prooxidant/antioxidant balance, therefore producing OS resulting in lung damage, even after cessation of exposure to the contaminants [17-19]. 

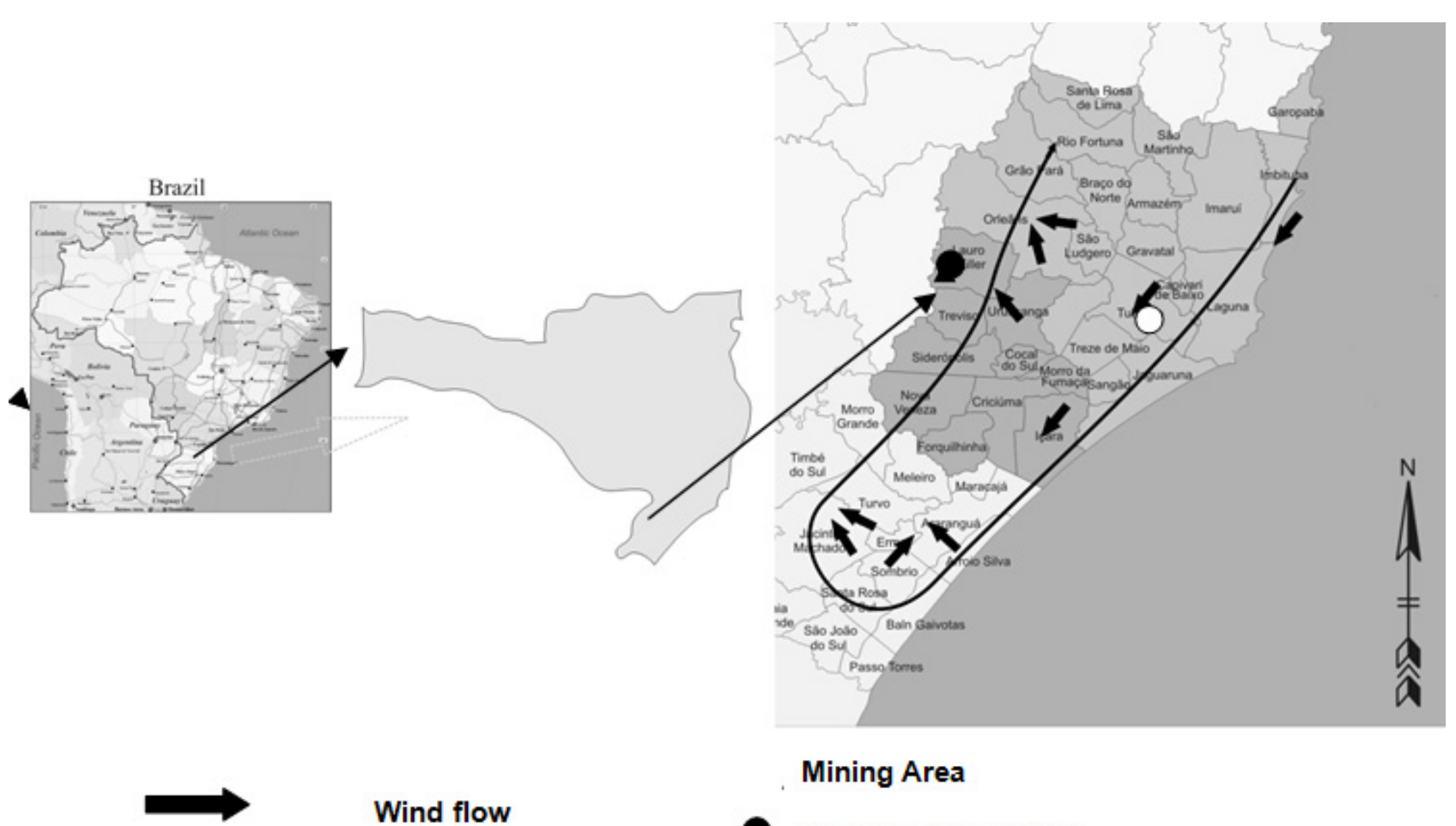

\section{Mining Area}

\section{City of Lauro Müller}

\section{City of Capivari de Baixo; Eletric power plant}

Figure 1. Geographic localization of the cities of Lauro Müller/Mining area, Capivari de Baixo/SRHS Incinerator and Laguna/Electric power-plant.

Around $30 \%$ of the local medical procedures from Lauro Müller was caused by respiratory diseases and $4 \%$ related to different kinds of cancer in this region [20]. In this regard, occupational exposure to metals, particularly in coal mining is considered to be the major cause of metal-exposed cancer [21]. Accordingly, atmospheric pollution has been studied and described as a possible cause of increases in morbidity for lung diseases and mortality for tumors in epidemiological data [20]. In our first publication OS markers found in workers directly exposed, i.e., one group working in the mine surface, the other working inside the galleries (underground workers), were very similar to those found in subjects living relatively near $(15 \mathrm{~km})$ the mining area compared to controls (blood donors living in the city in Florianópolis, $150 \mathrm{~km}$ away from the mines) [1]. All the exposed subjects showed enhanced plasma TBARS levels, an OS marker of lipid oxidation. Similar results were also found in coal mining workers at early stages of pneumoconiosis [10], and also in rats exposed to coal mine ambience [22]. Interestingly, in the late study, after treatment with the antioxidant erdosteine, levels of lipoperoxidation were similar to those of controls. More concerned were the results obtained in rats exposed to silica inhalation, the animals exhibited a progressive ROS overgeneration and lung damage even after the cessation of contaminant exposure [23]. In this regard, in our study no subjects showed pneumoconiosis in both exposed groups, workers and residents, not presenting any inflammatory disease in their lungs, despite that a systemic OS was detected in all subjects examined. It is well known that the chronic exposure to metals leads to metal-induced ROS overgeneration and ultimately to carcinogenesis [6]. Several deleterious metals, are usually present in coal mining ambience that are important source for metal-induced diseases related to this occupational contamination.

Indeed, determination of heavy metal contents carried out in urine samples through atomic mass spectroscopy revealed higher contents in exposed workers compared to controls. Lead contents in underground $(159.0 \%)$ and surface mine workers $(326.4 \%)$, and also in subjects living at the vicinity of the mines $(151.4 \%)$ were much higher compared to controls. Copper, zinc and iron concentrations were also elevated in the urine of both exposed groups of coal extraction workers, surface and underground miners, while only copper was elevated in the urine of subjects living near from mining plant [4]. Surprisingly, manganese showed decreased concentrations in the urine of the exposed mining workers [4]. In a related study high OS was detected in workers of a zinc recovery industrial plant as well as in workers of a secondary copper smelting plant in Taiwan [24]. As a consequence, levels of plasma $\alpha$-tocoferol detected in underground workers $(\cong 10 \mu \mathrm{M})$ showed around half the values found in controls $(\cong 20 \mu \mathrm{M})$. Despite the fact that no significant differences were detected, surface workers and residents living near the mining area showed values intermediary $(\cong 15 \mu \mathrm{M})$ to those found in underground workers, revealing that this nutritional antioxidant is being depleted in both groups. The similar profile obtained for vitamin $\mathrm{E}$ and total and also for reduced glutathione (GSH; Figure 2) contents reinforces the concept that all these 
subjects are facing a systemic OS, in which both antioxidants are probably counteracting excess of ROS generation associated with the chronic exposure to coal dust.

In addition, several other OS markers were changed compared to controls, as follows. GST activity, an important component of phase II enzymes of the biotransformation of xenobiotics, was elevated in both groups directly and indirectly exposed to mining activity, although GSH depletion was detected in all groups examined. The important endogenous antioxidant GSH is a cofactor necessary for GST to conjugate and eliminate xenobiotics [6]. It can be inferred that in these last subjects GST is given a better compensatory response to the oxidative insult. Interestingly, subjects living near the mining plant showed the highest GST values compared to both worker groups.

However, in a related study, decreased GST activity was found in erythrocytes of subjects in early stages of pneumoconiosis compared with miners not diagnosed for this disease [11]. Anyway, the increased GST activities found in all exposed groups of our study might reflect a response for an adequate maintenance of the biotransformation process, together with the additional capacity of GST to detoxify hydroperoxides derived from lipoperoxidation processes [6].

In accordance to our findings, Evelo and collaborators [11] also revealed a decreased GPx activity concomitantly to decreased GSH contents in erythrocytes of coal miners at early stages of pneumoconiosis. Catalase activity was increased in directly exposed coal miners, but only underground workers showed decreased GPx activity. In this regard, GPx inhibition seems to be consistent with chronic exposure to airborne contaminants [10,13], which will consequently render higher hydroperoxide levels inside the cells. In the presence of transition metal ions, such as ferrous or cuprous ions, $\mathrm{H}_{2} \mathrm{O}_{2}$ is converted to the most deleterious radical hydroxyl $\left(\mathrm{HO}^{\circ}\right)$, via the Fenton reaction [6]. There is evidence that inhalation of toxic occupational and environmental pollutants leads to excessive in vitro and in vivo generation of $\mathrm{HO}^{\bullet}$ radicals during the process of phagocytosis [17].

SOD activity was also inhibited in all groups examined and a similar response was also found in other studies involving coal mining workers $[10,13]$. On the other hand, rats exposed sub-chronically to a mine ambience showed SOD and GPx induction at the first week followed by SOD inhibition at the fourth week of exposure [22]. Accordingly, coal miners showed a progressive loss of an adequate antioxidant compensation regarding SOD and GPx activities in plasma, which were parallel to the tissue damage [10]. This apparent decrease of an adequate antioxidant response was accompanied by persistent high lipoperoxidation levels in plasma, resembling the general OS profile found in our study involving chronic exposure to mine ambience [1].

In summary, chronic exposure to airborne contaminants associated with coal extraction leads to a progressive decline in the antioxidant capacity (or systemic OS) present in the blood of both workers, directly or indirectly exposed to such PM contamination. A chronic systemic OS in turn will favor a cascade of events, involving synthesis of inflammatory factors, exacerbating inflammation in lungs, which can lead to cancer and other chronic lung diseases. The results also showed that people indirectly exposed to the mine ambience living in the vicinity of the mine area revealed a very similar profile regarding the systemic OS, being in great health risk associated with coal mining-related diseases.

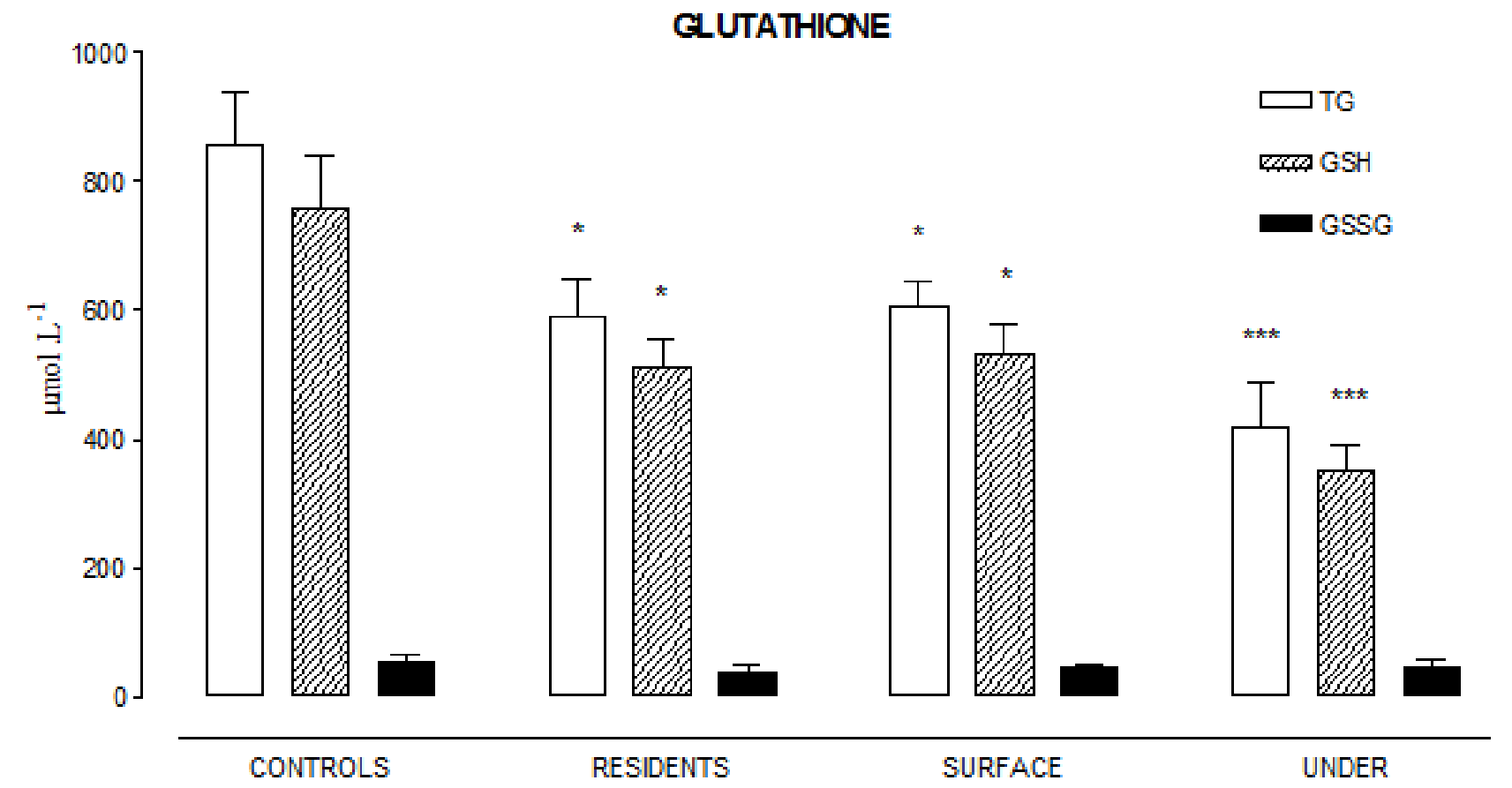

Figure 2. Total, reduced and oxidized glutathione (TG, GSH and GSSG; $\mu \mathrm{mol} \mathrm{ml}^{-1}$ ) contents in whole blood of subjects exposed to coal emissions and controls. Values as means $\pm \operatorname{SE}(n=20) ;\left(^{*}\right) \mathrm{p}<0.05$ in relation to controls. 


\subsubsection{After the Antioxidant Intervention}

The first finding regarding coal extraction, was a systemic OS present in the blood or workers directly or indirectly exposed to PM emissions related to coal mining [1], in general accordance to the related literature $[10,13,16]$. More importantly, they also revealed that people living in the vicinity $(c a .15 \mathrm{~km})$ of the mining area are also facing a systemic OS and risk of coal mining-related diseases.

An additional important finding the antioxidant intervention carried after the detection of the systemic OS was able to significantly attenuate such systemic OS. After a six-month period combining a daily antioxidant intervention with vitamins $E$ and $C$ ( $800 \mathrm{mg}$ and $500 \mathrm{mg}$, respectively), a general improvement was achieved both in enzymatic and non-enzymatic antioxidant defenses present in the blood of subjects exposed to mining activities [4]. Similarly, Pinho and collaborators [25] showed decreased pulmonary oxidative stress biomarkers in rats exposed to coal dust using $\mathrm{N}$-acetylcysteine (NAC) and deferoxamine as antioxidants.

Before the antioxidant supplementation, the concomitant enhancement of OS biomarkers as the plasma contents of TBARS and protein carbonyls, as well as the decrease found in the content of protein thiols, were all reversed after the antioxidant intervention in both groups of coal mining workers [4]. Moreover, after the antioxidant supplementation GSH contents in whole blood and vitamin E contents in plasma were also recovered, while the antioxidant enzymes showed a general enhanced activity compared to values found before the supplementation, indicating that the antioxidant supplementation was beneficial to recover the reductive power of the blood in all exposed groups [4].

The decreased values found in TBARS and PC levels after the antioxidant supplementation are probably due to the quenching ability of the liposoluble antioxidant $\alpha$-tocopherol, which acts blocking the propagation of lipoperoxidation in cell membranes. The interception of the peroxyl radical (ROO•) by $\alpha$-tocopherol results in the formation of the tocopheroxyl radical, which in turn is regenerated back to a-tocopherol by ascorbate, reduced glutathione or ubiquinol [6]. Also, vitamin C might act as a possible lead chelator showing a similar capacity of that of EDTA [26].

A remarkable increased SOD activity was found in subjects exposed to coal mining extraction after the antioxidant intervention compared to the lowered values found before such supplementation [4]. The decreased SOD activity found in the group of subjects living near the mines before the antioxidant intervention might be explained by the inhibition of heavy metals in important antioxidant enzymes $[27,28]$. The in vitro inhibition of GPx, SOD and GR activity was demonstrated by Hatzis and collaborators [27] after exposure to three different of PM (fly ashes from residual oil combustion, urban particulate matter and volcanic particulate ashes). Before the antioxidant intervention GST activities increased in all groups when compared to controls [4]. After supplementation the profile of GST activities was similar to that of GPx activities. In this regard, it was observed an increase in GST activity concomitant to depletion in GSH contents in cell cultures exposed to heavy metals that elicit OS [25].

\subsection{Coal Combustion: OS before and after an Antioxidant Intervention}

\subsubsection{Before the Antioxidant Intervention}

Air emissions from coal electric-power plants depend mainly on three factors, composition of burned mineral coal, type processing and alternative of combustion. Dispersion of air pollutants will depend on the height of the chimney, meteorology and topography of the region where the plant is localized [14] (Figure 1). Also, production of energy from mineral coal through combustion generates two types of ashes, the ultrafine particles and the fly ashes or particulate matter $(\mathrm{PM})$ around $0.1 \mu \mathrm{m}$ size, which are considered the most harmful because of their high content of redox-cycling organic chemicals [30], and also metals capable of producing ROS and OS. The proposed mechanism for the damage effects of exposure to mineral coal dust appears to be linked with the activation of macrophages and polymorphonuclears, thereby releasing mediators of the inflammatory response, which also include ROS overgeneration [31]. Furthermore, an inflamed lung is prone to exacerbate further oxidative damage derived from a broader range of PM [31].

Atmospheric pollution has been described as a possible cause of increases in morbidity for lung diseases and mortality for tumors in epidemiological data, including the regions of coal extraction and coal burning in southern Brazil [20]. Dust inhalation for long periods emitted by coal mining and coal burning lead to several lung pathologies, such as bronchitis, asthma, cancer, fibrosis, emphysema and pneumoconiosis, triggering a chronic inflammatory process, which is activated and linked to increased ROS generation and therefore systemic OS [18]. Moreover, several prospective studies have suggested that air pollution may be responsible for increased risk of developing lung cancer and cardiovascular diseases, among others, linking these risks with PM exposure and with ROS overgeneration [27,29,30].

Similarly to the results found in the contamination related to coal mining extraction [1], our group found that coal combustion was also capable to induce a similar OS in the blood of subjects exposed directly (working closed to the burning area) or indirectly (working at the administration building, $c a$. $0.3 \mathrm{~km}$, or living in the vicinity, $c a .2 \mathrm{~km}$ away of the electric-power plant) to the PM emissions associated to coal burning [3]. The electric-power plant is localized in the city of Capivari de Baixo ( 25,000 inhabitants), southern part of the Santa Catarina state, south Brazil $\left(28^{\circ} 27^{\prime} 5^{\prime \prime} \mathrm{S} ; 48^{\circ} 58^{\prime} 8^{\prime \prime} \mathrm{W}\right)$. The wind regime prevails northeast direction most part of the year, and such conditions favor a persistent exposure of its population to air contaminants emitted by the coal burning process, 
similarly to the emissions from a mining area localized in the city of Lauro Müller [1], ca.50 km from Capivari de Baixo (Figure 1).

Before the supplementation with vitamins $\mathrm{E}$ and $\mathrm{C}$, TBARS and PC levels were significantly increased, levels of GSH and vitamin E were decreased, while the activities of SOD and CAT were increased in workers and GST was increased in all groups compared to controls [3]. SOD activity was augmented in blood of mining workers with subsequent progression of pneumoconiosis compared with those without progression in a five years of follow-up study [18], as well as in rat lungs exposed for one week to coal mining ambience [22]. After the antioxidant intervention essentially all these OS biomarkers were normalized to control levels [3] (see details below). Thus the antioxidant intervention was able to confer a protective effect against the oxidative insult associated with airborne contamination derived from emissions of an electric power plant, in a way very similar to the results obtained in other projects carried out by our research group involving other chronic diseases, such as chronic cardiopathy associated with Chaga's disease [32] and also patients with chronic hepatitis C [33], using the same protocol for antioxidant intervention.

\subsubsection{After the Antioxidant Intervention}

Among several other metals PM bears high concentrations of iron, which might elicit the formation of hydroxyl radical thus damaging DNA, proteins and lipids [6]. Accordingly, other study found that lipoperoxidation induced by exposure to coal dust might be linked to the amount of iron from coal mining areas [34]. Also, when were analyzed lung epithelial cells type II A549 exposed to 29 different coal samples from three different mining regions in USA, it was found that the iron chelating capacity and lipoperoxidation levels in those cells were significantly higher compared to control cells [35].

Before the antioxidant supplementation and well in line with the contents found in the blood for GSH and protein thiols, plasma $\alpha$-tocopherol contents were also decreased in both exposed groups to emissions from the coal electric-power plant (directly $51.2 \%$; indirectly $35.6 \%$ ), as well as in residents living in Capivari de Baixo (37.1\%) compared to controls [3]. After the supplementation these antioxidants reached values near those of controls in subjects from the resident group whereas the two directly exposed workers showed even higher improvements, again indicating the protective effect of the antioxidant intervention. The increased levels of plasma vitamin E contents measured in the subjects that participate in the study after six months of the antioxidant intervention was a clear indication that they followed the diary intake recommendation during all the experimental period. Supplementation with vitamin C combined with vitamin E has been used in studies from our laboratory due to the cooperative interaction between these two antioxidants, vitamin $\mathrm{E}$ as an important free radical chain-breaker, while vitamin $\mathrm{C}$ regenerates the tocopheroxil radical produced during the detoxification of the lipoperoxidation process [6].

Before the antioxidant intervention SOD showed markedly enhanced activity in exposed workers (directly $139.4 \%$; indirectly $143.1 \%$ ), while in residents the increase (28.0\%) was not so pronounced compared to controls [3]. After the antioxidant supplementation, SOD values showed further increases in all groups (directly exposed 318.4\%; indirectly exposed $256.4 \%$; residents $54.4 \%$ ) compared to controls, suggesting an apparent beneficial effect to compensate the chronic OS. However, CAT activity showed no difference in the resident group before the antioxidant intervention, while markedly increased values were detected in directly (134.2\%) and indirectly (127.8\%) exposed workers compared to controls. GPx showed decreased activity in all exposed groups, also resembling the profile found in underground workers exposed to coal extraction [1], as in individuals exposed to SHSR incineration [2]. Similarly, Nadif and collaborators [13] found lower GPx activity in the blood from active miners compared to retired ones. GR activity showed decreased values only in subjects directly exposed (34.7\%) compared to controls, which were recovered to control values after the antioxidant intervention. GST activity was markedly increased in all groups examined (directly 220.5\%; indirectly exposed $270.3 \%$; residents $111.9 \%$ ), compared to controls [3]. After supplementation, GST activities returned to values similar to those of controls, resembling the behavior found in the other OS biomarkers.

In summary, workers directly or indirectly exposed to coal burning emissions from an electric-power plant, as well as subjects living near to the emissions showed a similar oxidative stress condition, which was attenuated by the antioxidant intervention carried out during six months. The intervention of vitamin $\mathrm{E}$ and $\mathrm{C}$ after this period revealed a general improvement both in enzymatic and non-enzymatic antioxidant defenses present in the blood of exposed subjects. More specifically, the antioxidant supplementation was able to attenuate the lipoperoxidation process by lowering TBARS contents as well as protein oxidation by lowering PC levels in plasma. Moreover, after supplementation whole blood GSH contents and vitamin E contents in plasma were recovered while the antioxidant enzymes showed a general compensation compared to activity values found before the antioxidant supplementation [3]. These results resemble those obtained for subjects exposed to coal extraction [1], strongly suggesting that irrespective of the source of coal emission the related contaminants produce a similar antioxidant response characterized by a systemic OS.

\subsection{SRHS Incineration: Systemic OS before and after an Antioxidant Intervention}

\subsubsection{Before the Antioxidant Intervention}

One of the most useful methods for elimination of Solid 
Residues of Health Services (SRHS) is incineration. However, it also provokes the emission of several hazardous air contaminants such as heavy metals, furans and dioxins, among others, which produce ROS overgeneration and therefore a systemic OS. Very similar to the results found in subjects exposed to the activities of coal extraction and coal combustion [1], the same enzymatic and non-enzymatic OS biomarkers present in the blood were examined in three different groups: workers directly exposed to SRHS incineration ( $c a .0 .1 \mathrm{~km}$ from the incinerator), indirectly exposed (residents living $c a .5 \mathrm{~km}$ from the incineration site), and controls (living ca. $150 \mathrm{~km}$ from the incineration site). In short, the results also revealed that subjects directly or indirectly exposed to SRHS are facing an oxidative insult, consequently being in health risk regarding fly ashes from SRHS incineration [2].

Municipal solid waste incinerators (MSWI) in different countries revealed a very similar pattern of dioxin generation, implying that such airborne contaminants are produced through the same mechanism, regardless the composition of solid wastes and the incinerator design [36]. Considering such similarity among MSWI, it is reasonable to assume that the incineration of SHRS behave in a similar way to validate comparisons between data from MSWI and SHRS. Nevertheless, the industrial incinerator seems to be even more harmful compared to MSWI, because the contents of dioxin and malondialdehyde, the major end-product of the oxidation of lipids, detected in subjects living near an industrial waste incinerator were higher compared to subjects living near a MSWI [37]. In addition, people living near an industrial area containing incinerators seem to accumulate more dioxin in their sera compared to subjects residing in a rural area from Belgium [38].

Considering that the process of incineration is growing in many countries [37,39], and despite that in the last two decades a decline in dioxin levels was detected in some countries [38,40,41], this industrial activity is still a matter of public concern. An important local increase in morbidity and mortality in the city of Capivari de Baixo occurred in the recent years, the mortality numbers were closely related to tumors, different from data of the whole country where tumors are the third cause of mortality [20]. This anomaly numbers of public health triggered the study related to contamination by fly ashes from SHRS incineration developed by our group [2].

Materials included in fly ashes from SHRS, such as heavy metals, PCDDs, PCDFs and probably PAHs [42,43] are prone to accumulate, and accumulation will increase proportionally to the duration of the exposure to fly ashes both in subjects directly and also indirectly exposed, such as the population living near the incinerator [44]. In this regard, subjects from our study were exposed for around five years in average, whilst the workers were exposed for almost 4 years [2]. Such exposure period is relatively short compared to other related studies, but considering the fact that dioxins are very persistent both in the environment and also in animal tissues [40], they consequently increases the risk of OS and the development of several diseases even during short exposure periods.

Concerning the contamination of heavy metals, a similar profile for lead concentrations detected in coal mining workers [1], although not so pronounced, was found in the urine of workers $(45.5 \%)$ of incineration of SRHS as well as in people not directly exposed and living in vicinal areas (98.6\%) when compared to controls [2]. Accumulation of these metals in humans increases ROS production, causing a severe systemic OS $[29,45]$. In addition, in vitro studies have shown that a high copper cellular environment favor cancer cells to proliferate into tumors [46]. On the other hand, iron concentrations were significantly increased only in the blood of workers directly exposed to SRHS incineration but not in people living in the vicinity when compared to controls [2], very similar to the profile obtained in the urine of coal mining workers and subjects living in the neighborhood [1](Ávila Jr. et al., 2009). Enhanced zinc concentrations were also found in incineration workers $(60.8 \%)$ and residents (87.9\%) when compared to controls [2], 2009). Similarly, a similar study revealed increased levels of $\mathrm{Cd}, \mathrm{Hg}$ and $\mathrm{Pb}$ in subjects indirectly exposed to solid waste incineration in Portugal [47]. According to Wang and Fowler [48], chronic exposure to $\mathrm{Pb}, \mathrm{Cd}$ and As induces $\mathrm{OS}$ by inhibition of important antioxidant enzymes.

In our study people exposed directly and indirectly exposed to SHRS showed a similar OS profile, suggesting a close correlation between the exposure to the incineration of SRHS and the response obtained from different OS biomarkers in both groups [2]. Except for GR activity all other biomarkers examined were altered both in workers and also in indirectly exposed subjects to SRHS emissions. While GST activity was increased and GPx was decreased in both exposed groups, CAT activity was increased and SOD activity was decreased only in workers. The contents of vitamin E and GSH were depleted and TBARS and GSSG levels (the oxidized form of glutathione, an excellent OS biomarker) showed increased values in plasma (Figure 3) of both workers and subjects living near the emissions, when compared to controls [2]. This elevated TBARS contents are well in line with the results found in workers and residents exposed to mining activity [1]. A similar profile was also obtained regarding plasma contents of vitamin $\mathrm{E}$ and whole blood contents of GSH in both groups exposed to coal extraction [1]. The depletion of these two important non-enzymatic antioxidants together with the persistent high lipoperoxidation levels found in both studies strongly indicates a condition of a chronic and severe systemic OS in all exposed subjects. Compare the glutathione profile (Figure 3) with the related response obtained for subjects exposed to coal mining emissions [1] (Figure 2). 


\section{GLUTATHIONE}

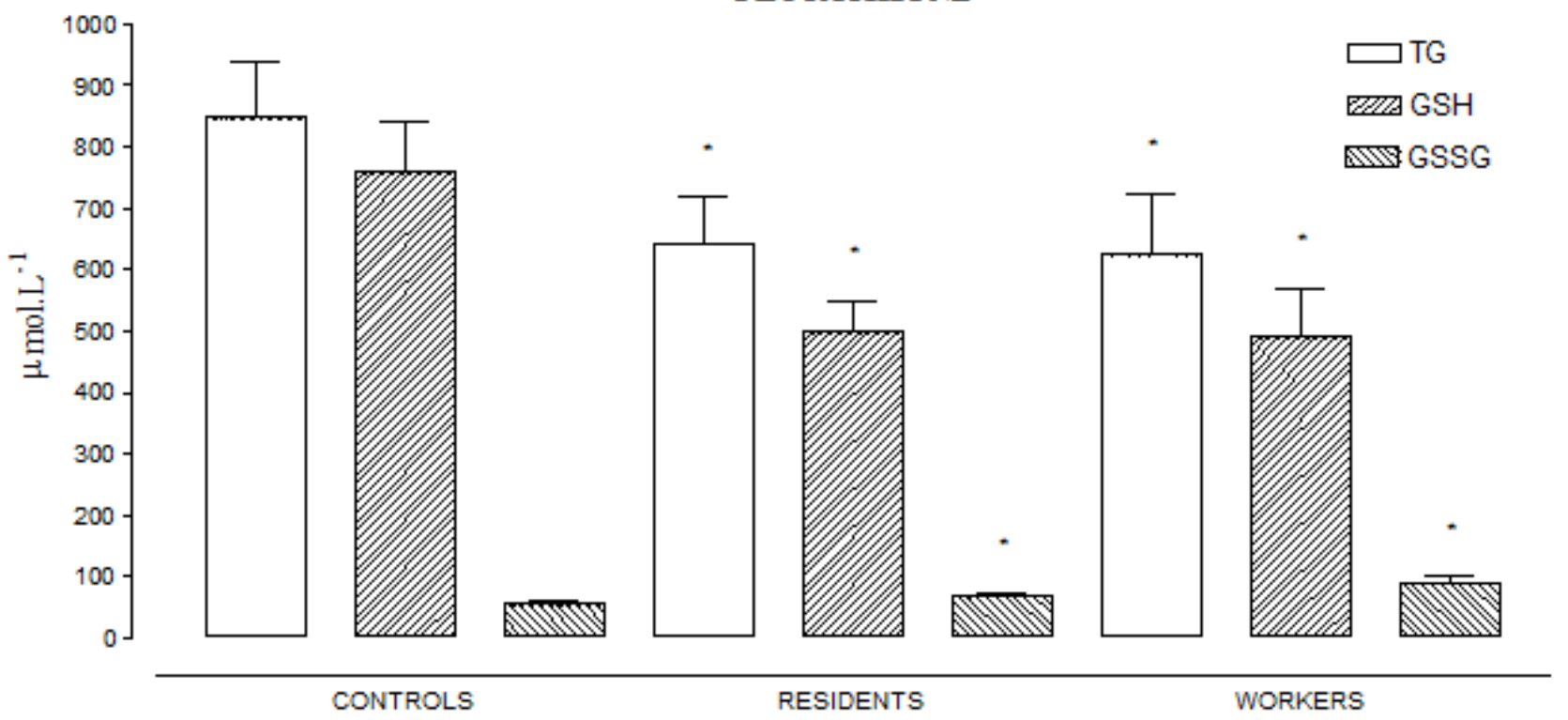

Figure 3. Total, reduced and oxidized glutathione (TG, GSH and GSSG, respectively; $\mu$ mol L ${ }^{-1}$ ) contents in whole blood of subjects exposed to SHSR incineration and controls. Values as means $\pm \mathrm{SE}(\mathrm{n}=20) ;(*) \mathrm{p}<0.05$ in relation to controls.

Surprisingly, while SOD activity was decreased, CAT activity was enhanced in workers exposed to SHRS incineration, and the same response was also obtained in workers exposed to mining acitvity [1]. Rats exposed sub-chronically to a mine ambience showed SOD and GPx increases after the first week followed by SOD inhibition after the fourth week of exposure [22]. Accordingly, coal miners showed a progressive loss of an adequate antioxidant compensation regarding SOD and GPx activity measured in plasma [10]. Taken all these results into consideration, it is possibly to suggest that irrespective to the kind of airborne contamination, time of exposure is determinant, while acute exposure elicits an apparent antioxidant enzymatic compensation chronic exposure seems to indicate a loss of adequate compensation.

In a related study, increased lipid peroxidation in workers and residents were also found, and the authors also suggested that that effect was related by hazardous substances emitted by the incinerator [37]. Under long-term exposure, the oxidative damage may inhibit cell-mediated immunity, cause DNA damage, and induce the development of tumors [49]. In particular, dioxins are able to directly or indirectly generate ROS and to induce carcinogenesis, and the main route of ROS generation is probably via biotransformation of xenobiotics through the induction of the phase I super-family of CYP450 enzymes together with the phase II family of glutathione S-transferases and other related enzymes [50,51]. Accordingly, GST activity was increased both in workers and residents exposed to SRHS emissions. Interestingly, despite GSH depletion verified in all groups examined, it seems that all these subjects are apparently still able to compensate the xenobiotic insult, keeping sustained high GST activities. A similar GST profile was obtained in residents and workers exposed to emissions from a mine plant [1].

\subsubsection{After the Antioxidant Intervention}

Except for the decreased manganese contents, all other heavy metal concentrations were elevated in all groups exposed to both sources of airborne contamination when compared to controls [1]. TBARS and PC concentrations, which were elevated before the antioxidant intervention, were significantly decreased after the antioxidant supplementation. Similarly, the contents of vitamin E and GSH, which were decreased before the antioxidant intervention, reached values near those found in controls, while SOD, CAT and GST activities were reestablished in all groups, showing values similar to those before such intervention. The results showed that the systemic OS detected previous to the vitamin supplementation in directly and indirectly subjects exposed to the airborne contamination from SRHS incineration (as well as from coal dust), was attenuated after the antioxidant intervention [4].

After six months of intervention with the nutritional antioxidants vitamins $\mathrm{E}$ and $\mathrm{C}$, workers and residents exposed to incineration of SHRS [4], showed a compensatory antioxidant response, again resembling the effect obtained in subjects exposed to coal extraction [1], as well as those exposed to the emissions from an electric-power plant [3]. It is worth to stress out again that all these studies carried out by our laboratory always used the same protocol and the same experimental design, showing that irrespective of the PM contamination, a very similar response of OS biomarkers was elicited after chronic exposure to different PM emissions.

As mentioned before in this review, other similar studies on coal mining workers and workers from waste incinerators are well in line with our results obtained in different OS 
biomarkers. The novel aspect found by our laboratory is that the antioxidant therapy with vitamins $\mathrm{E}$ and $\mathrm{C}$ is effective in attenuating the blood oxidative insult derived from coal extraction and combustion, and also from SRHS incineration, and that such nutritional intervention might be recommended for subjects exposed to these airborne contaminations [4].

Irrespective of the controversy involving health risks related to dioxin exposure [52], this study reinforced the conclusion already described in the literature, that a severe OS is present in the blood not only of workers directly exposed, but also in residents near a SRHS incineration plant. A possible relationship between systemic OS can be attributable to the relatively high incidence of cancer epidemiology in the region where the study was carried out (more pronounced in the city of Capivari de Baixo). Local authorities should establish further studies on the risks involved with incineration emissions from SRHS and propose urgent solutions regarding a public health policy in the region regarding such environmental contamination.

\section{Conclusions}

The results clearly indicate that supplementation with antioxidant vitamins could be recommended in order to attenuate the deleterious consequences of a systemic OS associated with such PM emissions.

\section{Concluding Remarks}

Several meta-analyses studies point out that antioxidant interventions with ascorbate, $b$-carotene and $\alpha$-tocopherol, as well with other antioxidants, sometimes fail to show positive effects in some chronic human diseases, especially concerning cardiovascular diseases [6,53-58]. In contrast, the studies from our laboratory indicate that the antioxidant therapy with vitamins $\mathrm{E}$ and $\mathrm{C}$ during six months was effective in significantly attenuating the systemic blood oxidative insult associated with exposure to coal extraction and combustion, as well as to SRHS incineration, and that such nutritional intervention might be recommended for subjects exposed to these airborne contaminations. This antioxidant efficacy was already demonstrated in other diseases [56], as well by our research group in patients with chronic cardiopathy associated with Chagas' disease [32] and with hepatitis $\mathrm{C}$ [33], using the same protocol of antioxidant intervention. In this regard, among other aspects involving the experimental design and protocols used in related studies that may explain, at least in part, doses above $400 \mathrm{IU}$ of vitamin $\mathrm{E}$ are necessary to counteract elevated systemic OS in humans [55]. The early detection of biochemical markers such as the OS biomarkers used in related studies involving the contamination derived from coal extraction, coal burning, incineration of solid waste residues [44], among other PM emissions, will certainly help to avoid or attenuate the human risk of related occupational diseases. The concomitant use of appropriate guidelines to monitor the emissions from coal activity and SHRS incinerators, use of adequate work equipments as well as other prophylactic procedures, together with a better understanding of the relations between contaminants, ROS overproduction, OS generation and related diseases, as well as efficacy of antioxidant intervention, are urgently needed.

\section{Acknowledgements}

This research was supported by grants from CNPq/MCT-Brazil and UNESC-Brazil. DWF is recipient of a CNPq scholarship (proc. 300353/2012-0), and thanks grant from CAPES/Brazil to attend the congress held in Bari, Italy, where this study was presented.

\section{REFERENCES}

[1] S. Ávila Jr, F.P. Possamai, P. Budni, P. Backes, E.B. Parisotto, V.M. Rizelio, M.A. Torres, P. Colepicolo, D. Wilhelm Filho. Occupational airborne contamination in south Brazil: 1. Oxidative stress detected in the blood of coal miners, Ecotoxicology Vol. 18, 1150-1157, 2009.

[2] F.P. Possamai, S. Ávila Jr, P. Budni, P. Backes, E.B. Parisotto, V.M. Rizelio, M.A. Torres, P. Colepicolo, D. Wilhelm Filho. Occupational airborne contamination in South Brazil: 2. Oxidative stress detected in the blood of workers of incineration of hospital residues, Ecotoxicology Vol. 18, 1158-1164, 2009.

[3] F.P. Possamai, S. Ávila Jr, E.B. Parisotto, A.M. Moratelli, D. Wilhelm Filho. Antioxidant intervention compensates oxidative stress in blood of subjects exposed to emissions from a coal electric-power plant in South Brazil, Environmental Toxicology and Applied Pharmacology Vol. 30,175-180, 2010 .

[4] D. Wilhelm Filho, S. Ávila Jr, F.P. Possamai, E.B., A.M. Moratelli, T.R. Garlet, D.B. Inacio, M.A. Torres, P. Colepicolo, F. Dal-Pizzol. Antioxidant therapy attenuates oxidative stress in the blood of subjects exposed to occupational airborne contamination from coal mining extraction and incineration of hospital residues, Ecotoxicology Vol. 19: 1193-1200, 2010.

[5] H. Sies. Oxidative stress. Academic Press, London, 1985.

[6] B. Halliwell, J.M.C. Gutteridge. Free Radicals in Biology and Medicine, $4^{\text {th }}$ ed. Oxford Science Publications, Oxford, 2007.

[7] A. Boveris, E. Cadenas. Cellular sources and steady-state levels of reactive oxygen species. In: L. Clerck, D. Massaro (Eds.). Oxygen, gene expression and cellular, Vol. 105. Marcel Dekker, New York, 1-25, 1997.

[8] S. Becker, J.M. Soukup, J.E. Gallagher. Differential particulate air pollution induced oxidant stress in human granulocytes, monocytes and alveolar macrophages. Toxicology in Vitro, Vol. 16:209-218, 2002.

[9] J.J. Engelen, P.J. Borm, M. Van-Sprundel, L. Leenaerts. Blood anti-oxidant parameters at different stages of pneumoconiosis in coal workers. Environmental Health Perspectives, Vol. 84:165-172, 1909. 
[10] R Altin, F Armutcu, L. Kart, A. Gurel, A. Savranlar, H. Özdemir. Antioxidant response at early stages and low grades of simple coal worker's pneumoconiosis diagnosed by high resolution computed tomography. International Journal of Hygiene and Environmental Health, Vol. 207:455-462, 2004.

[11] C.T. Evelo, R.P. Bos, P.J. Borm. Decreased glutathione content and glutathione S-transferase activity in red blood cells of coal miners with early stages of pneumoconiosis. British Journal of Industrial Medicine, Vol. 50:633-636, 1993.

[12] R. Perrin-Nadif, G. Auburtin, M. Dusch, J.M. Porcher, J.M. Mur. Blood antioxidant enzymes as markers of exposure or effect in coal miners. Occupational Environment Medicine, Vol. 53:41-45, 1996.

[13] R. Nadif, M.P. Oryszczyn, M. Fradier-Dusch, G. Hellier, J.P. Berttrand, Q.T. Pham, F. Kaufmann. Cross sectional and longitudinal study on selenium, glutathione peroxidase, smoking, and occupational exposure in coal miners. Occupational Environment Mediciine, Vol. 58:239-245, 2001.

[14] M.A. Monteiro, S.M.A. Furtado. O clima do trecho Florianópolis-Porto Alegre: uma abordagem dinâmica. Geosul, Vol. 19/20:117-133, 1995.

[15] J. Schwartz, D.W. Dockery, L.M. Neas. Is daily mortality specifically with fine particles? Journal of Air Waste Management Association, Vol. 46:927-939, 1996.

[16] M. Sorensen, R.P.F. Schins, O. Hertel, S. Loft. Transition metals in personal samples of PM 2.5 and oxidative stress in human volunteers. Cancer Epidemiology Biomarkers Prevention, Vol. 14(5):1340-1343, 2005.

[17] M.B. Kadiiska, R.P. Mason, K.L. Dreher, D.L. Costa, A.J. Ghio. In vivo evidence of free radical formation in the rat lung after exposure to an emission source air pollution particle. Chemical Research in Toxicology, Vol. 10:1104-1108, 1997.

[18] R.P. Schins, P.J. Borm. Mechanisms and mediators in coal dust induced toxicity: a review. Annals of Occupational Hygiene, Vol. 43:7-33, 1999.

[19] P. Zeidler, A. Hubbs, L. Battelli, V. Castranova. Role of inducible nitric oxide synthase-derived nitric oxide in silica-induced pulmonary inflammation and fibrosis. Journal of Toxicology and Environmental Health, Vol. 67:1001-1026, 2004.

[20] DATASUS. Caderno de Informações de Saúde. Online available from http: //tabnet.datasus. gov.br/cgi/cadernos/cadernosmap.htm of subordinate document. Accessed 15 May, 2008.

[21] K. Steenland, D. Loomis, C. Shy, N. Simonsen. Review of occupational lung carcinogens. American Journal of Industrial Medicine, Vol. 29:474-490, 1996.

[22] F. Armutcu, B.D. Gun, R. Altin, A. Gurel. Examination of lung toxicity, oxidant/antioxidant status and effect of erdosteine in rats kept in coal mine ambience. Environmental Toxicology and Pharmacology, Vol. 24: 106-113, 2007.

[23] D.W. Porter, L.L. Millecchia, P. Willard, V.A. Robinson, D. Ramsey, J. McLaurin, A. Khan, K. Brumbaugh, C.M. Beighley, A. Teass, V. Castranova. Nitric oxide and reactive oxygen species production causes progressive damage in rats after cessation of silica inhalation. Toxicology Science Vol.
90:188-197, 2006.

[24] H.L. Chen, C.Y. Hsu, D.Z. Hung, M.L. Hu. Lipid peroxidation and antioxidants status in workers exposed to $\mathrm{PCDD} / \mathrm{Fs}$ of metal recovery plants. Science of Total Environment Vol. 372:12-19, 2006.

[25] R.A. Pinho, P.C.L. Silveira, L.A. Silva, E.L. Streck, F. Dal-Pizzol, J.C.F Moreira. N-Acetylcysteine and deferoxamine reduce pulmonary oxidative stress and inflammation in rats after coal dust exposure. Environmental Research Vol. 99: 355-360, 2005.

[26] S.J.S. Flora, M. Mittal, A. Mehta. Heavy metal induced oxidative stress and its possible reversal by chelation therapy. Indian Journal of Medical Research Vol. 128:501-523, 2008.

[27] C. Hatzis, J.J. Godleski, B. González-Flecha B, J.M. Wolfson, P. Koutrakis. Ambient particulate matter exhibits direct inhibitory on oxidative stress enzymes. Environ Sci Technol Vol. 40:2805-2811, 2006.

[28] G. Wang, B.A. Fowler. Roles of biomarkers in evaluating interactions among mixtures of lead, cadmium and arsenic. Toxicology and Applied Pharmacology Vol. 233(1): 92-99, 2008.

[29] H.M. Korashy, A.O.S El-Kadi. The role of redox-sensitive transcription factors NF- $\mathrm{KB}$ and $\mathrm{AP}-1$ in the modulation of the Cyplal gene by mercury, lead, and copper. Free Radical Biology and Medicine Vol. 44: 795-806, 2008.

[30] N. Li, T. Xia, A.E. Nel. The role of oxidative stress in ambient particulate matter-induced lung diseases and its implications in the toxicity of engineered nanoparticles. Free Radical Biology and Medicine Vol. 44, p. 1689-1699, 2008.

[31] S. Becker, J.M. Soukup, J.E. Gallagher. Differential particulate air pollution induced oxidant stress in human granulocytes, monocytes and alveolar macrophages. Toxicology In Vitro, Vol. 16: 209-218, 2002.

[32] C.M. Ribeiro, P. Budni, R.C. Pedrosa, M.S. Farias, E.B. Parisotto, E.M. Dalmarco, T.S. Fröde, D. Oliveira-Silva, P. Colepicolo, D. Wilhelm Filho. Antioxidant therapy attenuates oxidative insult caused by benzonidazole in chronic Chagas heart disease. International Journal of Cardiology, Vol. 145: 27-33, 2010.

[33] M.S. Farias, P. Budni, C.M. Ribeiro, E.B. Parisotto, C.E Santos, D.F. Dias, E.M. Dalmarco, T.S. Fröde, R.C. Pedrosa, D. Wilhelm Filho. Antioxidant supplementation attenuates oxidative stress in chronic hepatitis $\mathrm{C}$ patients. Gastroenterología y Hepatología, Vol. 35:386-394, 2012.

[34] N.S. Dalal, J. Newman, D. Pack, S. Leonard, V. Vallyathan. Hydroxyl radical generation by coal mine dust: possible implication to coal workers' pneumoconiosis (CWP). Free Radical Biology and Medicine, Vol.18: 11-20, 1995.

[35] Q. Zhang, X. Huang. Induction of ferritin and lipid peroxidation by coal samples with different prevalence of coal workers' pneumoconiosis: role of iron in the coals. American Journal of Industrial Medicine, Vol. 42:171-179, 2002.

[36] H.Y. Tong, F.W. Karasek. Comparison of PCDF in fly ash collected from municipal incinerators of different countries. Chemosphere, Vol. 15:9-12, 1986.

[37] J.H. Leem, Y.C. Hong, K.H. Lee, H.J. Kwon, Y.S. Chang, J.Y. 
Jang. Health survey on workers and residents near the municipal waste and industrial waste incinerators in Korea. Industrial Health, Vol. 41:181-188, 2003.

[38] S. Fierens, H. Mairesse, C. Hermans, A. Bernard, G. Eppe, J.F. Focant, E.D. Pauw. Dioxin accumulation in residents around incinerators. Journal of Toxicology and Environmental Health, Vol. 66 (14): 1287-1293, 2003.

[39] J.H. Kuo, H.H. Tseng, P.S. Rao, M.Y. Wey. The prospect and development of incinerators for municipal solid waste treatment and characteristics of their pollutants in Taiwan. Applied Thermal Engineering, Vol. 28(17-18):2305-2314, 2008.

[40] S.M. Hays, L.L. Aylward. Dioxin risks in perspective: past, present, and future. Regulatory. Toxicolology and Pharmacology, Vol. 37: 202-217, 2003.

[41] S. Augusto, P. Pinho, C. Branquinho, M.J. Pereira, A. Soares, F. Catarino. Atmospheric dioxin and furan deposition in relation to land-use and other pollutants: a survey with lichens. Journal of Atmospheric Chemistry, Vol. 49:53-65, 2004.

[42] G.W. Sovocool, R.K. Mitchum, Y. Tondeur, W.D. Munslow, T.L. Vonnahme, J.R. Donnelly. Bromo- and bromochloro-polynuclear aromatic hydrocarbons, dioxins and dibenzofurans in municipal incinerator fly ash. Biomedical Environmental Mass Spectrometry, Vol.15:669676, 1988.

[43] K.J. Hong, S. Tokunaga, T. Kajiuchi. Extration of heavy metals from MSW incineration fly ashes by chelating agents. Journal of Hazard Material, Vol. 75:57-73, 2000.

[44] R. Yoshida, Y. Ogawa. Oxidative stress induced by 2,3,7,8-tetrachlorodibenzo- $p$-dioxin: an application of oxidative stress markers to cancer risk assessment of dioxins. Industrial Health, Vol. 38:5-14, 2000.

[45] L.M. Gaetke, C.K. Chow CK. Copper toxicity, oxidative stress, and antioxidant nutrients. Toxicology, Vol. 189(12):147-163, 2003.

[46] M. Valko, C.J. Rhodes, J. Moncol, M. Izakovic, M. Mazur. Free radicals, metals and antioxidants in oxidative stress-induced cancer. Chemical Biological Interactions, Vol. 160:1-40, 2006.

[47] M.F. Reis, C. Sampaio, A. Brantes, P. Aniceto, M. Melim, L. Cardoso, C. Gabriel, F. Simão, J.P. Miguel. Human exposure to heavy metals in the vicinity of Portuguese solid waste incinerators-Part 1: Biomonitoring of $\mathrm{Pb}, \mathrm{Cd}$ and $\mathrm{Hg}$ in blood of the general population. International Journal of Hygenic Environmental Health, Vol. 210:439-446, 2007.

[48] G. Wang, B.A. Fowler. Roles of biomarkers in evaluating interactions among mixtures of lead, cadmium and arsenic. Toxicolology and Applied Pharmacology, Vol. 233(1):92-99, 2008.

[49] C.N. Ong, H.M. Shen HM, S.E. Chia. Biomarkers for male reproductive health hazards: are they available? Toxicology Letters, Vol. 134:17-30, 2002.

[50] R.W. Nims, R.A. Lubet. The CYP2B subfamily. In: Ioannides C (Eds). Cytochromes P450: metabolic and toxicological aspects. CRC, Boca Raton, 135-160, 1996.

[51] R. Yoshida, Y. Ogawa, I. Mori, A. Nakata, R. Wang, S. Ueno, I. Shioji, N. Hisanaga. Associations between oxidative stress levels and total duration of engagement in jobs with exposure to fly ash among workers at municipal solid waste incinerators. Mutagenesis, Vol. 18(6):533-537, 2003.

[52] P. Cole, D. Trichopoulos, H. Pastides, T. Starr, J.S. Mandel. Dioxin and cancer: a critical review. Regulatory Toxicology and Pharmacology, Vol. 38:378-388, 2003.

[53] C.A. Rice-Evans, A.T. Diplock. Current status of antioxidant therapy. Free Radical Biology and Medicine, Vol. 15:77-96, 1993.

[54] R. Brigelius-Flohé. Vitamin E: the shrew waiting to be tamed. Free Radical Biology and Medicine, Vol. 46:543-554, 2009.

[55] L.J. RobertsII, J.A. Oates, M.F. Linton MF, S. Fazio, B.P. Meador, M.D. Gross, Y. Shyr, J.D. Morrow. The relationship between dose of vitamin $\mathrm{E}$ and suppression of oxidative stress in humans. Free Radical in Biology and Medicine, Vol.43:1388-1393, 2007

[56] L.J. RobertsII, M.G. Traber. Vitamins E and C in the prevention of cardiovascular disease and cancer in men. Free Radical in Biology and Medicine, Vol.46:1558-1567, 2009.

[57] M.G. Traber, J. Atkinson. Vitamin E, antioxidant and nothing more. Free Radical in Biology and Medicine Vol. 43:4-15, 2007.

[58] J.M. Zingg. Vitamin E: an overview of major research directions. Molecular Aspects in Medicine, Vol. 28:400-422, 2007. 